Arq. Bras. Med. Vet. Zootec., v.66, n.3, p.894-902, 2014

\title{
Diferentes níveis de incorporação de farinha de resíduos de jundiás (Rhamdia quelen) cultivados na dieta
}

[Different levels of jundiá waste meal in the diet]

\author{
S. Rossato ${ }^{1}$, R. Lazzari $^{2 *}$, I. Liberalesso de Freitas ${ }^{3}$, D. Maschio ${ }^{1}$, V. Corrêia ${ }^{l}$, \\ J. Radünz Neto ${ }^{4}$
}

\author{
${ }^{1}$ Aluno de pós-graduação - UFSM - Santa Maria, RS \\ ${ }^{2}$ Universidade Federal de Santa Maria - UFSM - Palmeira das Missões, RS \\ ${ }^{3}$ Aluna de graduação - UFSM - Santa Maria, RS \\ ${ }^{4}$ Universidade Federal de Santa Maria - UFSM - Santa Maria, RS
}

\begin{abstract}
RESUMO
O estudo foi desenvolvido no Laboratório de Piscicultura do Departamento de Zootecnia da Universidade Federal de Santa Maria, com duração de oito semanas, de abril a junho de 2011. O objetivo foi definir o melhor nível de incorporação do resíduo de peixes na alimentação de juvenis de jundiá, em sistema de

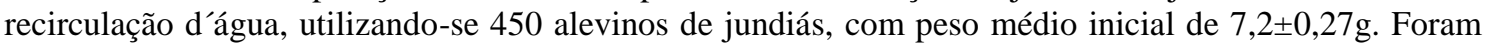
testadas cinco diferentes dietas, em três repetições, com níveis diferentes $(0 ; 3,75 ; 7,5 ; 15$; e $30 \%)$ de incorporação de farinha de carcaça de jundiás com vísceras (FCJCV). As dietas continham, aproximadamente, $37 \%$ de PB e $3200 \mathrm{kcal}$ de EM $/ \mathrm{kg}$ de dieta. Foram coletados dados de ganho em peso diário, sobrevivência, fator de condição, taxa de crescimento específico, conversão alimentar aparente, rendimento de carcaça, taxa de eficiência proteica e deposição de proteína e lipídio corporal. O maior ganho de peso foi para o nível 30\% de inclusão de FCJCV, com peso final de 45,47g e ganho em peso diário de 0,68g/dia. A dieta com nível de 30\% de inclusão de FCJCV apresentou melhores valores para taxa de crescimento específico (3,34\%/dia), conversão alimentar aparente (1,05: 1), biomassa final $1.105,45 \mathrm{~g}$, deposição proteica corporal $(64,9 \mathrm{mg} / \mathrm{dia})$, taxa de eficiência proteica $(1,9)$ e coeficiente de retenção proteica $(1,96 \%)$. Concluiu-se que a utilização de farinha de resíduos de processamento de jundiá no nível de $30 \%$ de inclusão na dieta foi a que apresentou maior eficiência no desenvolvimento de juvenis de jundiá.
\end{abstract}

Palavras-chave: farinha de peixe, ganho em peso, crescimento, eficiência proteica

\begin{abstract}
The study was carried out at the Fish Farming Laboratory of the Animal Science Department, Federal University of Santa Maria, during 8 weeks, from April to June 2011. The objective of this study was to define the best level of incorporation of waste in food fish of juvenile Jundia in water recirculation system using 450 fingerlings of jundia with initial average weight of $7.2 \pm 0.27 g$. We tested 5 different diets in three repetitions with different levels of incorporation of carcasse jundiá with viscera meal $(F C J C V)(0$, $3.75,7.5,15$, and 30\%). The diets contained 37\% CP and 3200kcal/kg of ME. Data were collected from daily weight gain, survival, condition factor, specific growth rate, feed conversion, carcass yield, protein efficiency ratio and deposition of body protein and lipid. The weight gain was greater with the inclusion of $30 \%$ FCJCV with final weight of $45.47 \mathrm{~g}$ and daily weight gain of $0.68 \mathrm{~g} / \mathrm{day}$. The diet with inclusion of $30 \%$ FCJCV showed better values for specific growth rate (3.34\%/day), feed conversion ratio (1.05: 1), final biomass (1105.45g), body protein deposition (64.9mg/day), protein efficiency ratio (1.9) and protein retention coefficient (1.96\%). In conclusion, the use of processing waste meal of jundia in the level of $30 \%$ in the diet showed the highest efficiency in the development of juvenile jundiá.
\end{abstract}

Keywords: fish meal, weight gain, growth, protein efficiency

Recebido em 6 de maio de 2012

Aceito em 12 de dezembro de 2013

${ }^{*}$ Autor para correspondência (corresponding author)

E-mail: rlazzari@ufsm.br 


\section{INTRODUÇÃO}

O aproveitamento de resíduos no ciclo de produção de pescado no Brasil ainda é pouco significativo. Apenas na indústria de conservas estes resíduos são utilizados para a elaboração de farinha de pescado, representando um sério problema para a planta industrial, principalmente por serem poluentes e de difícil descarte (Guilherme et al., 2006). Segundo Tacon e Metian (2008), a aquicultura mundial consumiu, em 2006, 3,724 milhões de toneladas de farinha de peixe, 835 mil toneladas de óleo de peixe e o equivalente a 16,6 milhões de toneladas de farinha de peixe tipo resíduo.

O uso de subprodutos de origem animal é uma alternativa para minimizar a escassez de produtos de alta qualidade proteica, além de otimizar a redução do volume de resíduos oriundos do processamento de pescado, diminuindo, assim, o problema de poluição ambiental (Godoy et al., 2008). A seleção de ingredientes para a formulação de dietas para peixes tem sido baseada no custo da proteína e da energia e no perfil de aminoácidos (Teixeira et al., 2006).

As rações para peixes caracterizam-se pela elevada porcentagem de proteína. Para que os peixes consigam crescer adequadamente, eles precisam obter, na proteína dos alimentos, os aminoácidos necessários para a construção do seu tecido muscular e a produção de outras proteínas importantes para o funcionamento do seu organismo (Guilherme et al., 2006). O desenvolvimento de rações comerciais para peixes tem sido tradicionalmente baseado em farinha de peixe pela sua alta concentração de proteína e bom balanceamento de aminoácidos essenciais (Teixeira et al., 2006). Em virtude da alta porcentagem de alimentos de origem animal, constituem problemas dessas rações os altos teores de minerais, como cálcio e fósforo, e o alto custo de algumas dessas fontes, como a farinha de peixe de boa qualidade (Meurer et al., 2008).

O jundiá (Rhamdia quelen) é uma espécie onívora bem adaptada a receber rações comerciais, apresentando bom crescimento em cultivo. É bem aceito pelos consumidores por ter uma carne de ótima qualidade, sabor e não apresentar espinha em formas de Y. Seu crescimento é mais acentuado quando lhe são ofertados alimentos de origem animal, confirmando sua tendência à carnivoria (Oliveira Filho e Fracalossi, 2006).

O objetivo deste trabalho foi definir o nível adequado de incorporação do resíduo de peixe na alimentação de juvenis de jundiá.

\section{MATERIAL E MÉTODOS}

O presente estudo foi desenvolvido no Laboratório de Nutrição de Peixes, Setor de Piscicultura do Departamento de Zootecnia da Universidade Federal de Santa Maria (altitude $95 \mathrm{~m}, 2^{\circ} 43^{\prime} \mathrm{S}, 53^{\circ} 42^{\prime} \mathrm{W}$ ), com duração de oito semanas, de abril a junho de 2011.

Os procedimentos experimentais foram aprovados no Comitê Interno de Ética em Experimentação Animal - UFSM (protocolo $\left.n^{\circ} .86 / 2010\right)$.

Foi utilizado um sistema de recirculação composto de 15 tanques de polipropileno (280 L). A temperatura da água $\left(20^{\circ} \mathrm{C}\right)$ foi mantida durante o período experimental por meio de resistências $(4000 \mathrm{~W})$ e termostato localizados no reservatório principal (2000L). O sistema foi composto de dois filtros biológicos e sistemas individuais de abastecimento e escoamento. A oxigenação da água foi feita por um sistema de aeração tipo "Venturi" (Radünz Neto et al., 1987), localizado no reservatório principal, e nos tanques, com o auxílio de aeradores individuais.

Foram utilizados 450 juvenis de jundiás (peso inicial $=7,2 \pm 0,27 \mathrm{~g}$, comprimento inicial $=9,28 \pm 0,16 \mathrm{~cm}$, 30 peixes por tanque), com idade aproximada de 90 dias. Os peixes passaram por um período de 10 dias de adaptação às condições experimentais, tendo sido alimentados com a dieta controle (30\% de FCJCV = farinha de carcaça de jundiás com vísceras). Antes do início do experimento, os peixes receberam banho profilático com permanganato de potássio $(2 \mathrm{mg} / \mathrm{L})$ para prevenir focos de bactérias.

Diariamente, a qualidade da água foi monitorada por meio de análises de temperatura $\left({ }^{\circ} \mathrm{C}\right) \mathrm{e}$ oxigênio dissolvido ( $\mathrm{mg} / \mathrm{L})$, usando-se oxímetro digital (YSI 550), e, semanalmente, foram aferidos os demais parâmetros, como $\mathrm{pH}$, alcalinidade $\left(\mathrm{mg} / \mathrm{L} \quad \mathrm{CaCO}_{3}\right)$, dureza $(\mathrm{mg} / \mathrm{L}$ $\mathrm{CaCO}_{3}$ ), amônia $(\mathrm{mg} / \mathrm{L})$ e nitrito $(\mathrm{mg} / \mathrm{L})$, com o auxílio de kits colorimétricos. 
Neste estudo, foram testados cinco diferentes dietas, em três repetições, com níveis diferentes $(0$; 3,$75 ; 7,5 ; 15$ e $30 \%$ ) de incorporação de farinha de carcaça de jundiás com vísceras (FCJCV). As dietas foram formuladas para conter $37 \%$ de $\mathrm{PB}$ e $3200 \mathrm{kcal}$ de EM/kg de dieta (Meyer e Fracalossi, 2004).

As dietas foram preparadas, mediante moagem, pesagem e mistura dos ingredientes secos, em amassadeira elétrica. Quando estes estavam bem homogeneizados, adicionou-se o óleo, se necessário, misturando-se novamente até a completa homogeneização. Então, foi adicionada água $(40 \%)$ em temperatura ambiente. A mistura úmida foi peletizada em moedor de carne e seca em estufa com circulação de ar forçada a $50^{\circ} \mathrm{C}$ por 24 horas. Após secas, as rações foram armazenadas em freezer $\left(-18^{\circ} \mathrm{C}\right)$ até o momento de fornecimento aos animais.

Os animais foram alimentados três vezes ao dia (nove, 13 e 17 horas), com alimentação restrita. $\mathrm{Na}$ primeira e segunda semanas, receberam $6 \%$ do peso vivo (PV); na terceira semana $5 \%$ do $\mathrm{PV}$; na quarta semana $4,5 \%$ do PV; na quinta e sexta semanas $4 \%$ do PV; na sétima e oitava semanas $3,5 \%$ do PV. Os animais foram anestesiados por hipotermia em solução de água e gelo (1:1) e abatidos por secção medular.

A análise de composição centesimal foi realizada a partir da coleta inicial de uma amostra de 30 peixes e a cada quatro semanas (dois peixes por unidade experimental), tendo sido obtidos dados de umidade, proteína, lipídio e cinzas. Essas análises foram realizadas de acordo com metodologias recomendadas pela AOAC (1995), e o lipídio foi extraído e quantificado pelo método de Bligh e Dyer (1959).

Com base nos resultados de proteína e lipídio, foram calculados os índices de deposição de proteína e lipídio corporal: deposição de proteína corporal $(\mathrm{g}): \mathrm{DPC}=[\mathrm{Pf} *(\% \mathrm{PBCf} / 100)]-[\mathrm{Pi} *$ (\%PBCi /100)]; deposição de lipídio corporal (g): $\mathrm{DGC}=[\mathrm{Pf} *(\% \mathrm{GCf} / 100)]-[\mathrm{Pi} *(\% \mathrm{GCi} / 100)] ;$ sendo $\mathrm{PBCi}=$ proteína corporal inicial; $\mathrm{PBCf}=$ proteína corporal final; $\mathrm{PBc}$ : proteína bruta da dieta; GCi: lipídio corporal inicial; e GCf: lipídio corporal final.

O acompanhamento do crescimento e a estimativa do consumo de ração pelos animais foram obtidos a cada quatro semanas, por meio de biometrias, em que foram coletados os seguintes dados: peso: peso do peixe inteiro (g); comprimento padrão e total $(\mathrm{cm})$; sobrevivência $(\%)$; fator de condição: $\mathrm{FC}=$ (pesox100)/ (comprimento total $\left.^{3}\right) ;$ taxa de crescimento específico $(\% / \mathrm{dia}): \mathrm{TCE}=[\ln ($ peso final) - ln (peso inicial)]/dias)*100; conversão alimentar aparente: CAA $=$ (consumo total)/(biomassa final - biomassa inicial); ganho em peso diário $(\mathrm{g})$ : e GPD = (peso final - peso inicial)/dias; biomassa total (g).

Os dados de peso de carcaça, peso de trato digestivo, comprimento de trato digestivo, peso da gordura visceral e peso de fígado foram coletados de dois peixes/caixa (oito peixes/ tratamento), abatidos e eviscerados no início, na quarta e oitava semanas experimentais. A partir destes resultados, foram calculados os seguintes parâmetros: rendimento de carcaça $(\%): \mathrm{RC}=(($ peso eviscerado com cabeça e brânquias) / (peso inteiro))*100; índice digestivo somático (\%): IDS $=$ ((peso trato/peso inteiro) *100); índice hepatossomático $(\%):$ IHS $=$ (peso fígado/peso inteiro) $* 100$; índice de gordura visceral $(\%): \mathrm{IGV}=$ (peso da gordura visceral/peso inteiro) $* 100$; taxa de eficiência proteica $($ TEP $)=$ ganho em peso/quantidade de proteína consumida e coeficiente de retenção proteica $(\mathrm{CRP})=(100 *(($ pesof $(\mathrm{g}) * \mathrm{PBcf})-$ (pesoi $(\mathrm{g}) * \mathrm{PBci}))) /($ consumo ração*PBd), sendo $\mathrm{PB}$ $=$ proteína bruta $; \mathrm{c}=$ corporal $; \mathrm{i}=$ inicial $; \mathrm{f}=$ final.

Os dados obtidos foram submetidos ao teste de normalidade de Shapiro-Wilk, sendo considerados de distribuição normal aqueles dados que apresentaram $\mathrm{P}>0,05$. Posteriormente, foi feita análise de regressão, em que foi utilizado o teste de Dunnett em nível de 5\% de significância. Todas as análises foram realizadas utilizando o pacote estatístico SAS (Statistical..., 2001).

\section{RESULTADOS E DISCUSSÃO}

Os parâmetros de qualidade da água se mantiveram em condições consideradas adequadas para a criação do jundiá (Rhamdia quelen) (Baldisserotto e Silva, 2004). A temperatura média da água foi $20,76^{\circ} \mathrm{C}$, o oxigênio dissolvido $6,59 \mathrm{mg} / \mathrm{L}$, o pH 7,3, a alcalinidade $37,7 \mathrm{mg} / \mathrm{L} \mathrm{CaCO}_{3}$, a dureza $37 \mathrm{mg} / \mathrm{L}$ $\mathrm{CaCO}_{3}$, a amônia $0,30 \mathrm{mg} / \mathrm{L}$ e o nitrito $0,05 \mathrm{mg} / \mathrm{L}$.

Ao final do período experimental (oito semanas), foi observado melhor desempenho dos animais conforme o aumento do nível de inclusão da farinha de carcaça de jundiás com vísceras (FCJCV) na dieta (Fig. 1). O maior peso final foi observado nos peixes alimentados com dietas contendo 30\% de inclusão de FCJCV $(45,47 \mathrm{~g})$. O ganho em peso, o comprimento total e o comprimento padrão seguiram a mesma tendência do ganho de peso, com maiores CT e CP observados com o aumento dos níveis de inclusão da FCJCV (Fig. 1). 

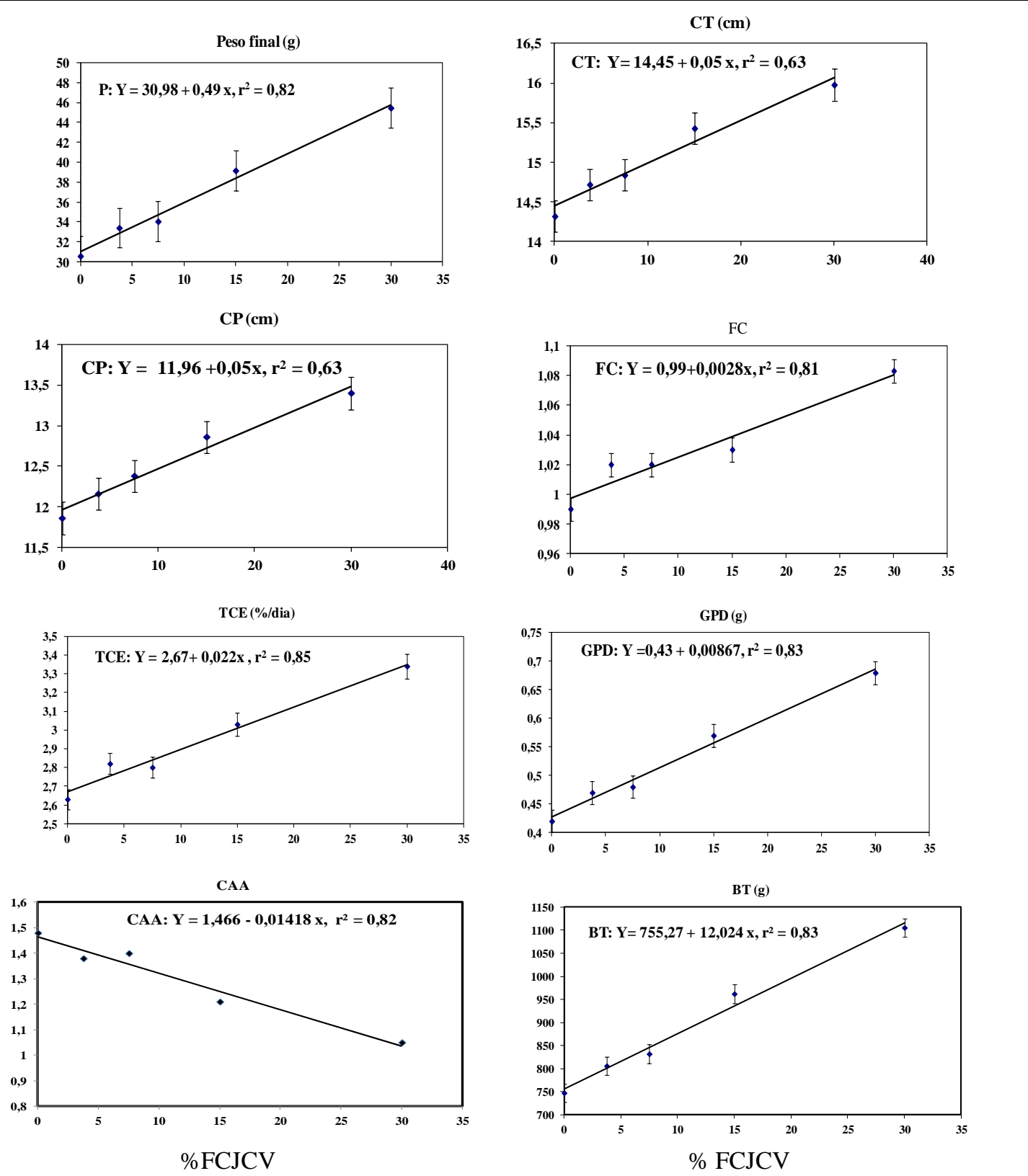

Figura 1. Parâmetros zootécnicos de juvenis de jundiás alimentados com dietas compostas de diferentes níveis de FCJCV após oito semanas experimentais.

Tratamentos: $0 \%, 3,75 \%, 7,5 \%, 15 \%$ e $30 \%$ de FCJCV: farinha de carcaça de jundiás com vísceras. Variáveis: peso final (g);CT: comprimento total; CP: comprimento padrão; GPD: ganho em peso diário TCE: taxa de crescimento específico; FC: fator de condição; CAA: conversão alimentar aparente; BT: biomassa total; efeito linear: P: Y=30,99 $+0,49 \mathrm{x}, \mathrm{r}^{2}: 0,82 ; \mathrm{CT}: \mathrm{Y}=14,45+0,05 \mathrm{x}, \mathrm{r}^{2}: 0,63 ; \mathrm{CP}: \mathrm{Y}=11,96+0,05 \mathrm{X}, \mathrm{r}^{2}=0,63 ; \quad \mathrm{FC}: \mathrm{Y}=0,99+0,00273 \mathrm{x}, \mathrm{r}^{2}: 0,81$; GPD: $Y=0,43+0,0087 X, r^{2}: 0,83$; TCE: $Y=2,67+0,022 X, r^{2}: 0,85$; CAA: $Y=1,08-0,009 x, r^{2}: 0,80$; BT: $Y=755,27+$ $12,02 \mathrm{X}, \mathrm{r}^{2}: 0,83$.

Pela formulação da dieta (Tab. 1), pode-se observar maior quantidade de lisina nos tratamentos em que foi adicionado maior percentual da farinha de resíduo de peixe (30\% de FCJCV), o que pode ter contribuído para o melhor desempenho dos animais. Às outras dietas foram adicionados aminoácidos sintéticos para suprir a exigência, uma vez eles podem ser mais rapidamente absorvidos no trato gastrintestinal do que os aminoácidos ligados a proteínas (National..., 2011), o que explica o 
desempenho inferior. Outro fator que pode ter influenciado é a possibilidade de maior lixiviação dos aminoácidos sintéticos. Zarate e Lovell (1997) constataram lixiviação de $13 \%$ da lisina sintética da dieta 15 segundos após o contato com a água, enquanto apenas $2 \%$ da lisina ligada à proteína foi lixiviada.

Tabela 1. Dietas compostas de diferentes níveis de FCJCV utilizadas para a alimentação de juvenis de jundiás ${ }^{1}$

\begin{tabular}{|c|c|c|c|c|c|}
\hline \multicolumn{6}{|c|}{ Formulação da dieta ${ }^{1}(\%)$} \\
\hline \multirow{2}{*}{ Ingredientes } & \multicolumn{5}{|c|}{ FCJCV } \\
\hline & $0 \%$ & $3,75 \%$ & $7,5 \%$ & $15 \%$ & $30 \%$ \\
\hline FCJCV & 0 & 3,75 & 7,5 & 15 & 30 \\
\hline CPS & 24,25 & 21,73 & 18,32 & 12,5 & 0 \\
\hline Farelo de soja & 31 & 31 & 31 & 31 & 31 \\
\hline Farelo de trigo & 8,49 & 8,49 & 8,49 & 8,49 & 8,49 \\
\hline Milho moído (grãos) & 19 & 19 & 19 & 19 & 19 \\
\hline Óleo de soja & 5,65 & 5 & 4,3 & 2,6 & 0 \\
\hline Vitaminas ${ }^{2}$ & 1 & 1 & 1 & 1 & 1 \\
\hline Minerais $^{2}$ & 1 & 1 & 1 & 1 & 1 \\
\hline Calcário calcítico & 0,7 & 1 & 1 & 1 & 1 \\
\hline Fosfato bicálcico & 3 & 2 & 2 & 0 & 0 \\
\hline Lisina & 3,84 & 3,71 & 3,6 & 3,36 & 2,9 \\
\hline Metionina & 1,56 & 1,55 & 1,55 & 1,72 & 1,56 \\
\hline Sal comum & 0,5 & 0,5 & 0,5 & 0,5 & 0,5 \\
\hline BHT & 0,01 & 0,01 & 0,01 & 0,01 & 0,01 \\
\hline Material inerte (areia) & 0 & 0,26 & 0,72 & 2,81 & 3,53 \\
\hline \multicolumn{6}{|c|}{ Composição da dieta (\%) } \\
\hline Massa seca $^{4}$ & 95 & 94,72 & 95,81 & 95,44 & 94,61 \\
\hline Proteína bruta $^{4}$ & 36,49 & 35,62 & 34,83 & 35,93 & 35,75 \\
\hline Lisina $^{3}$ & 5,80 & 5,80 & 5,80 & 5,80 & 5,80 \\
\hline Metionina $^{3}$ & 2,13 & 2,13 & 2,13 & 2,13 & 2,13 \\
\hline Metionina + cistina $^{3}$ & 0,27 & 0,27 & 0,28 & 0,28 & 0,30 \\
\hline Treonina $^{3}$ & 1,27 & 1,29 & 1,28 & 1,29 & 1,28 \\
\hline Triptofano $^{3}$ & 0,24 & 0,24 & 0,24 & 0,24 & 0,24 \\
\hline Valina $^{3}$ & 1,63 & 1,66 & 1,66 & 1,70 & 1,74 \\
\hline Isoleucina $^{3}$ & 1,44 & 1,45 & 1,44 & 1,44 & 1,41 \\
\hline Leucina $^{3}$ & 2,51 & 2,55 & 2,54 & 2,59 & 2,63 \\
\hline Fenilalanina $^{3}$ & 1,69 & 1,69 & 1,66 & 1,64 & 1,56 \\
\hline Histidina $^{3}$ & 0,90 & 0,91 & 0,90 & 0,90 & 0,89 \\
\hline Arginina $^{3}$ & 2,15 & 2,15 & 2,11 & 2,08 & 1,98 \\
\hline Lipídio $^{4}$ & 6,48 & 6,44 & 6,87 & 5,95 & 5,25 \\
\hline Fibra em detergente neutro ${ }^{4}$ & 15,76 & 15,45 & 15,31 & 15,65 & 13,22 \\
\hline Extrativos não nitrogenados ${ }^{4}$ & 33,54 & 34,23 & 33,48 & 31,22 & 31,83 \\
\hline Matéria mineral $^{4}$ & 7,73 & 8,26 & 9,51 & 11,25 & 13,95 \\
\hline Relação EM/PB & 87,20 & 90,16 & 92,13 & 89,29 & 90,95 \\
\hline Cálcio $^{4}$ & 1,22 & 1,23 & 1,36 & 1,15 & 1,70 \\
\hline Fósforo ${ }^{4}$ & 1,03 & 1,00 & 1,14 & 1,07 & 1,66 \\
\hline Relação Ca/P & 1,19 & 1,23 & 1,19 & 1,07 & 1,02 \\
\hline Energia metabolizável estimada $(\mathrm{kcal} / \mathrm{kg})^{5}$ & 3182 & 3212 & 3209 & 3208 & 3251 \\
\hline
\end{tabular}

${ }^{1}$ Dieta ajustada com base em Lazzari et al. (2008). ${ }^{2}$ Composição da mistura vitamínica e mineral (Mig Fish $1 \%$ de inclusão/Mig Plus®): ác. fólico: 299,88mg, ác. pantotênico:3000mg, cobalto: 60mg, cobre: 1000mg, colina: 103.500mg, ferro: $6.416 \mathrm{mg}$, biotina:0,06mg, iodo: 45,36mg, manganês: $8000,40 \mathrm{mg}$, magnésio: $5,10 \%$, selênio: 60,30mg, vit.A: 1.000 .000 UI, vit. B1: $1500,38 \mathrm{mg}$, vit. B2: $1500 \mathrm{mg}$, vit. B6: $1500,38 \mathrm{mg}$, vit. C: $15000 \mathrm{mg}$, vit. D: 240.000 UI, vit. E: $10.000 \mathrm{mg}$, vit. K: $400 \mathrm{mg}$, zinco: $14000 \mathrm{mg}$, inositol $10000 \mathrm{mg}$, niacina $9000 \mathrm{mg}$, enxofre $0,01 \%$, cloro 2,30\%. ${ }^{3}$ Calculado com base nas análises dos ingredientes. ${ }^{4}$ Analisada- Laboratório de Piscicultura DZ/UFSM. ${ }^{5}$ Energia metabolizável(EM) estimada com base nos valores fisiológicos padrões, i.e:,4kcal/g para proteínas e carboidratos digestíveis; 9kcal/g para lipídios (Lee e Putnam, 1973; Shyong et al.,1998). FCJCV: farinha de carcaça de jundiás com vísceras; BHT: antioxidante. CPS: concentrado proteico de soja. 
À dieta $30 \%$ de FCJCV não foi adicionado óleo de soja, pois a quantidade de energia foi suprida apenas com o percentual de óleo contido na FCJCV, e isso também pode ter contribuído para aumentar o desempenho, visto o óleo de peixe de água doce ser caracterizado por altas proporções de n-6 PUFA, especialmente ácido linoleico e ácido araquidônico (Souza et al., 2007), essenciais para o bom desenvolvimento dos peixes.

A conversão alimentar aparente (CAA) variou com a inclusão de FCJCV, tendo o aumento da inclusão de FCJCV feito com que a CAA se reduzisse (Fig. 1). A dieta com $30 \%$ de FCJCV obteve CAA de 1,05: 1 e a dieta com 0\% de FCJCV, CAA de 1,48: 1, valores estes considerados bons. Lazzari et al. (2007) encontraram valores de conversão alimentar para o tratamento com farinha de peixe e farelo de soja de 1,3:1, e consideraram este valor muito bom por se tratar de um peixe onívoro. Tais valores foram encontrados provavelmente devido a um ótimo controle de arraçoamento, em que os animais alimentados com a dieta $30 \%$ de FCJCV poderiam ter recebido uma quantidade maior de alimento, e com isso pode ter havido um ganho compensatório de peso.

A biomassa total inicial era de $210,62 \mathrm{~g}$; ao final das oito semanas experimentais, ela variou de $747,36 \mathrm{~g}$ no nível de $0 \%$ de FCJCV a 1.105,45g no nível de $30 \%$ de FCJCV (Fig. 1). A composição centesimal não variou muito entre os tratamentos, apenas foi observado um maior percentual de proteína no tratamento $30 \%$ de FCJCV.

O índice hepatossomático (Tab. 2) aumentou com o aumento da incorporação da farinha de resíduo de peixe. Segundo Faria et al. (2001), o aumento do índice hepatossomático pode estar relacionado com a necessidade de metabolização da proteína animal incluída nas rações, o que acarreta maior atividade do fígado e, consequentemente, aumento no tamanho desse órgão. $O$ rendimento de carcaça (Tab. 2) observado foi maior que o encontrado por Pedron et al. (2008) e semelhante ao encontrado por Losekann et al. (2008) e Corrêia et al. (2009), que afirmam ter o jundiá um bom potencial para a produção de carne.

Tabela 2. Composição centesimal, índices digestivos e hepáticos, rendimento de carcaça e sobrevivência dos juvenis de jundiás alimentados com dietas compostas de diferentes níveis de FCJCV após oito semanas experimentais

\begin{tabular}{|c|c|c|c|c|c|c|c|}
\hline \multirow[b]{2}{*}{ Variáveis } & \multirow[b]{2}{*}{ inicial } & \multicolumn{5}{|c|}{ FCJCV } & \multirow[b]{2}{*}{$\mathrm{P}$} \\
\hline & & 0 & 3,75 & 7,5 & 15 & 30 & \\
\hline & $13,77 \pm 0,49$ & & $15,48 \pm 0,79$ & & & & \\
\hline $\mathrm{PB}(\%)$ & & $15,31 \pm 0,49$ & * & $15,41 \pm 0,22 *$ & $15,31 \pm 0,66 *$ & $16,36 \pm 0,34 *$ & 0,0259 \\
\hline $\mathrm{CZ}(\%)$ & $2,87 \pm 0,24$ & $2,32 \pm 0,055$ & $2,26 \pm 0,24$ & $2,59 \pm 0,47$ & $2,52 \pm 0,043$ & $2,65 \pm 0,28$ & 0,0981 \\
\hline MS (\%) & $19,36 \pm 0,12$ & $22,62 \pm 0,77$ & $23,35 \pm 0,97$ & $22,58 \pm 1,90$ & $23,41 \pm 1,08$ & $23,99 \pm 1,57$ & 0,1792 \\
\hline Lipídios (\%) & $4,52 \pm 0,15$ & $5,26 \pm 0,79$ & $6,03 \pm 1,02$ & $5,64 \pm 0,84$ & $5,42 \pm 0,2$ & $5,07 \pm 0,58$ & 0,3208 \\
\hline IDS & & $1,14 \pm 0,14$ & $1,42 \pm 0,09$ & $1,23 \pm 0,07$ & $1,32 \pm 0,10$ & $1,51 \pm 0,11$ & 0,49 \\
\hline QI & & $1,17 \pm 0,12$ & $1,20 \pm 0,04$ & $1,29 \pm 0,133$ & $1,28 \pm 0,11$ & $1,35 \pm 0,13$ & 0,17 \\
\hline IHS & & $1,15 \pm 0,12$ & $1,42 \pm 0,09 *$ & $1,23 \pm 0,07 *$ & $1,31 \pm 0,10 *$ & $1,51 \pm 0,11 *$ & 0,024 \\
\hline IGV & & $0,79 \pm 0,15$ & $0,84 \pm 0,29$ & $0,60 \pm 0,24$ & $0,65 \pm 0,11$ & $0,71 \pm 0,06$ & 0,8 \\
\hline $\mathrm{RC}(\%)$ & & $87,89 \pm 1,47$ & $87,15 \pm 0,94$ & $86,89 \pm 0,73$ & $87,25 \pm 0,99$ & $88,24 \pm 1,11$ & 0,285 \\
\hline $\mathrm{S}(\%)$ & & $98,88 \pm 1,93$ & $97,77 \pm 1,93$ & $98,88 \pm 1,93$ & 100 & $98,88 \pm 1,93$ & 0,59 \\
\hline
\end{tabular}

Valores expressos como média terro-padrão da média (teste de Dunnett $\mathrm{P}<0,05$ ).

Tratamentos: 0\%, 3,75\%, 7,5\%, 15\% e 30\% de FCJCV: farinha de carcaça de jundiás com vísceras.

Variáveis: PB: proteína bruta; CZ: cinzas; MS: massa seca; lipídio; IDS: índice digestivo-somático; QI: quociente intestinal; IHS: índice hepatossomático; IGV: índice de gordura visceral; RC: rendimento de carcaça; S: sobrevivência; efeito linear: PB: $Y=15,21+0,032 x, r^{2}=0,327$, IHS: $Y=1,21+0,0816 x, r^{2}=0,41$.

A deposição de proteína corporal (Fig. 2) variou com o aumento do nível de inclusão de FCJCV: na dieta com menor inclusão ( $0 \%$ de FCJCV), houve menor deposição de proteína $(37,2 \mathrm{mg} / \mathrm{dia})$, e com maior inclusão $(30 \%$ de FCJCV), observou-se maior deposição proteica 
(64,9mg/dia). Bomfim et al. (2010), ao trabalharem com níveis de lisina na dieta para tilápias, encontraram valores de deposição proteica similares (47 a $73 \mathrm{mg} / \mathrm{dia})$.

A taxa de eficiência proteica (TEP) indica quanto da PB da dieta foi convertida em peso corporal. A maior TEP encontrada (Fig. 2) foi para o maior nível de inclusão de FCJCV $(1,9)$, e a pior TEP foi para o menor nível de inclusão de FCJCV $(1,15)$. O coeficiente de retenção proteica (CRP) (Fig. 2) seguiu a tendência linear dos demais parâmetros. Ocorreu variação nos valores de CRP de 1,24\% (sem FCJCV) até 1,96\% (nível de $30 \%$ de FCJCV).

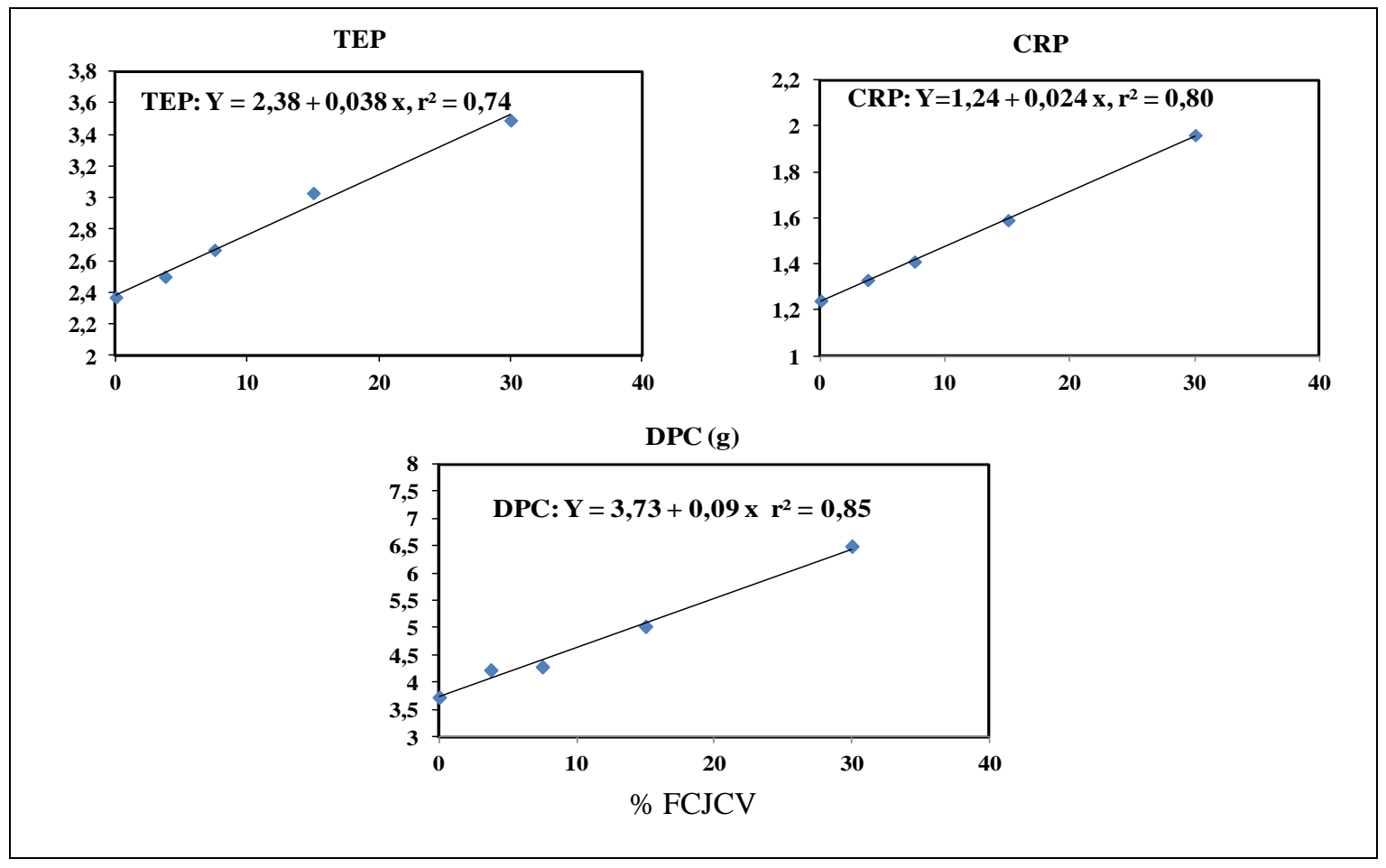

Figura 2. Índices de deposição de proteína corporal de juvenis de jundiás alimentados com dietas compostas de diferentes níveis de FCJCV após oito semanas experimentais.

Tratamentos: 0\%, 3,75\%, 7,5\%, 15\% e 30\% de FCJCV: farinha de carcaça de jundiás com vísceras (eixo $\mathrm{X}$ ); variáveis: DPC: deposição de proteína corporal; $\mathrm{TEP}=$ taxa de eficiência proteica; $\mathrm{CRP}=$ coeficiente de retenção proteica.

A farinha de peixe e seus subprodutos, como a farinha de peixe proveniente de resíduos de processamento de pescado, são importantes fontes proteicas na alimentação de peixes, sendo necessários estudos visando à determinação do nível ideal do seu uso nas rações para as diversas espécies utilizadas em aquicultura, em suas distintas fases de desenvolvimento (Faria et al., 2001).

O crescimento da aquicultura como agroindústria e a intensificação de estratégias de produção condicionaram a busca por ingredientes de alta qualidade que permitam a formulação e o processamento de dietas nutricionalmente completas e economicamente viáveis, a fim de maximizar a produção de pescado e minimizar o impacto ambiental de sistemas de produção (Cyrino et al., 2010).

\section{CONCLUSÃO}

A utilização da farinha de resíduos de processamento de jundiá no nível de $30 \%$ de incorporação na dieta proporciona maior eficiência alimentar de juvenis de jundiá. 


\section{AGRADECIMENTOS}

À Capes, pela bolsa de mestrado do primeiro autor, ao CNPq, pela bolsa de produtividade em pesquisa do Prof. João Radünz Neto e pela bolsa de iniciação científica da aluna Isadora Liberalesso de Freitas e a FAPERGS (processo 11/1175-1) pelo apoio financeiro.

\section{REFERÊNCIAS}

ASSOCIATION of Official Analytical Chemists - AOAC. Official methods of analysis. 16.ed. Washington: AOAC, 1995. 1137p.

BALDISSEROTTO, B.; SILVA, L.V.F. Qualidade da água. In: BALDISSEROTTO, B.; RADÜNZ NETO, J. Criação do jundiá. Santa Maria:UFSM, 2004. p.73-94.

BLIGH, E.G.; DYER, W.J. A rapid method of total lipid extraction and purification. Can. Jour. Biochem. Physiol., v.37, p.911-917, 1959.

BOMFIM, M.A.D.; LANNA, E.A.T.; DONZELE, J.L. et al. Níveis de lisina, com base no conceito de proteína ideal, em rações para alevinos de tilápiado-nilo. Rev. Bras. Zootec., v.39, p.1-8, 2010.

CORRÊIA, V.; RADÜNZ NETO, J.; LAZZARI, R. et al. Crescimento de jundiá e carpa húngara criados em sistema de recirculação de água. Cienc. Rural, v.39, p.1533-1539, 2009.

CYRINO, J.E.P.; BICUDO, Á.J.A.; SADO, R.Y. et al. A piscicultura e o ambiente - o uso de alimentos ambientalmente corretos em piscicultura. Rev. Bras. Zootec., v.39, p.68-87, 2010.

FARIA, A.C.E.A.; HAYASHI, C.; GALDIOLI, E.M.; SOARES, C.M. et al. Farinha de peixe em rações para alevinos de tilápia do Nilo, Oreochromis niloticus (L.), linhagem tailandesa. Act. Scient., v.23, p.903-908, 2001.

GODOY, H.B.R.; LANDELL FILHO, L.C.; BIANCHINI SOBRINHO, E.; GODOY, M.M. et al. O uso da silagem de subprodutos da filetagem de peixe na alimentação de suínos em crescimento - parâmetros séricos. Braz. Jour. Veter. Res. Anim. Sci., v.45, p.429-436, 2008.

GUILHERME，R.F.; CAVALHEIRO, J.M.O; SOUZA, P.A.S. Caracterização química e perfil aminoácidico da farinha de Silagem de cabeça de camarão. Cienc. Agrotec., v.31, p.793-797, 2006.
LAZZARI, R.; RADÜNZ NETO, J.; VEIVERBERG, C.A. et al. Alimentação do jundiá (Rhamdia quelen, Heptateridae) com ingredientes proteicos. Arch. Zoot., v.56, p.115-123, 2007.

LAZZARI, R.; RADÜNZ NETO, J.; PEDRON, F.A. et al. Desempenho e composição dos filés de jundiás (Rhamdia quelen) submetidos a diferentes dietas na fase de recria. Arq. Bras. Med. Vet. Zootec., v.60, p.477-484, 2008.

LEE, D.J.; PUTNAM, G.B. The response of rainbow trout to varying protein/energy ratios in a test diet. J. Nut., v.103, p.916-922, 1973.

LOSEKANN, M.E.; RADÜNZ NETO, J.; EMANUELLI, T. et al. Alimentação do jundiá com dietas contendo óleos de arroz, canola ou soja. Cienc. Rural, v.38, p.225-230, 2008.

MEYER, G.; FRACALOSSI, D.M. Protein requirement of jundiá fingerlings, Rhamdia quelen, at two dietary energy concentrations. Aquaculture, v.240, p.331-343, 2004.

MEURER, F.; HAYASHI, C.; BARBERO, L.M. et al. Farelo de soja na alimentação de tilápiasdo-nilo durante o período de reversão sexual. Rev. Bras. Zootec., v.37, p.791-794, 2008.

NATIONAL research council - NRC. Nutrient requirements of fish and shrimp. Washington, D.C., 2011. 376p.

OLIVEIRA FILHO, P.R.C.; FRACALOSSI, D.M. Coeficientes de digestibilidade aparente de ingredientes para juvenis de jundiá. Rev. Bras. Zootec., v.35, p.1581-1587, 2006.

PEDRON, F.A.; RADÜNZ NETO, J.; EMANUELLI, T. et al. Cultivo de jundiás alimentados com dietas com casca de soja ou de algodão. Pesq. Agropec. Bras., v.43, p.93-98, 2008.

RADÜNZ NETO, J.; KOHLER, C.C.; LEWIS, W.M. Water re-use system of fingerling fishes in Brasil with emphasis on South American catfishes (Rhamdia quelen and R. sapo). Trop. Agric., v.64, p.2-6, 1987.

SHYONG, W.J.; HUANG, C.H.; CHEN, H.C. Effects of dietary protein concentration on growth and muscle composition of juvenile Zacco barbata. Aquaculture, v.167, p.35-42, 1998. 
SOUZA, S.M.G.; ANIDO, R.J.V.; TOGNON, F.C. Ácidos graxos ômega-3 e ômega-6 na nutrição de peixes - fontes e relações. Rev. Cienc. Agrov., v.6, p.63-71, 2007.

STATISTICAL ANALYSIS SYSTEM - SAS. User's Guide. Version 8.02. SAS Institute INC. North Caroline, SAS, 2001. 3864p.

TACON, A.G.J.; METIAN, M. Global overview on the use of fish meal and fish oil in industrially compounded aquafeeds: Trends and future prospects. Aquaculture, v.285, p.146-158, 2008.
TEIXEIRA, E.A.; CREPALDI, D.V.; FARIA, P.M.C. et al. Substituição de farinha de peixes em rações para peixes. Rev. Bras. Rep. Anim., v.30, p.118-125, 2006.

ZARATE, D.D.; LOVELL, R.T. Free lysine (Llysine. $\mathrm{HCl}$ ) is utilized for growth less efficiently than protein-bound lysine (soybean meal) in practical diets by young channel catfish (Ictalurus punctatus). Aquaculture, v.159, p.87100, 1997. 